\title{
Challenges of Management of Duplex System Ureterocele in an 18-Year-Old Woman: A Case Report
}

\author{
Abubakar Sadiq Muhammad* and Khalid Abdullahi \\ Usmanu Danfodiyo University Teaching Hospital Sokoto, Nigeria.
}

*Corresponding author: Dr. Abubakar Sadiq Muhammad, Department of

Surgery, Usmanu Danfodiyo University Teaching Hospital Sokoto, Nigeria.

Received Date: February 26, 2021

Published Date: March 24, 2021

\begin{abstract}
Background: Ureterocele is a cystic dilatation of the intravesical part of the ureter. Duplex system ureterocele is rare and occur more in females. Patients usually present with recurrent abdominal pain and urinary tract infection. The diagnosis and the treatment of duplex system ureterocele in women may pose diagnostic and therapeutic dilemma. We report a case of duplex system ureterocele in a woman highlighting diagnostic and therapeutic challenges.

Case report: This is 18-year-old woman who presented with recurrent right flank pain, intermittent fever of 7 months duration and lower urinary tract symptoms. There was right renal angle tenderness on abdominal examination. Abdominopelvic ultrasound and computerized tomographic scan urogram (CTU) revealed right hydronephrosis and a ureterocele. Accurate diagnosis was missed by all the imaging studies done. She had excision of the ureterocele and common sheath reimplantation of the two ureters on account of duplex system ureterocele. She had uneventful recovery. The urethral catheter, stents, drain and the stitches were remove 15 and 16 days postoperatively. She was discharged 20 days post operatively.

Conclusion: Duplex system ureterocele may present with recurrent pyelonephritis. Computerized tomographic scan urogram is necessary for accurate diagnosis. There may be diagnostic and or therapeutic challenges. Common sheath ureteral reimplantation is associated with good outcome.
\end{abstract}

Keywords: Duplex system; challenges; management; ureterocele; woman; cystic dilatation

Abbreviations: CTU: Computerized Tomographic Scan Urogram; IVU: Intravenous Urogram; DMSA: Dimercaptosuccinic Acid

\section{Introduction}

Ureterocele is cystic dilatation and outpouching of the intra vesical part of the ureter [1]. The incidence of ureterocele in the new born range from $1 / 500$ to $1 / 4000$ and female are affected 4-7times more than males [2]. Duplex system ureterocele occur in $1 \%$ of the population and in relation to upper moiety ureter in $80 \%$ of the cases [3]. Bilateral ureterocele occur in $10 \%$ of the cases [4]. When the diagnosis is missed in childhood, the patients may later present with recurrent infection, septicemia, stone and renal failure [5]. High index of suspicion is required for accurate diagnosis [5]. Embryologically, duplex system arises when 2 ureteric buds emerge from the distal part of mesonephric duct. The future lower

moiety ureter separates from the Wolffian duct early and attaches to the future urinary bladder in the urogenital sinus superior laterally acquiring short intravesical course making it prone to reflux [1]. While the upper moiety ureteric bud separates lately from the mesonephric duct, therefore acquiring long intravesical course and draining into the urinary bladder inferior and medial to the lower moiety ureter [1]. The upper moiety ureter is associated with ectopia and ureterocele as postulated in the WeighertMeyer rule [6]. However, Stephen described an exception to this rule [7]. Stephen's ectopic pathway states that the ectopic ureter may not only insert distal to the normal ureteric orifice but may 
insert superior-medially violating Weighert-Meyer rule $[8,9]$. The development of ureterocele has been linked to failure of Chwalla membrane to perforate at the utero-trigonal junction leading to the obstruction and cystic dilatation of the intravesical ureter [1]. Is not all ureterocele that are obstructed, therefore other theories that try to explain the development of ureterocele include aberrant signaling, incomplete muscular development and that of dilatation of the intramural ureter [6]. Ureterocele is classified in relation to the renal unit or configuration, and location of ureteric orifice [1]. In relation to the renal unit, ureterocele can be single -system or duplex system ureterocele. Intravesical (orthotopic) is typically associated with single system in adults [5] while extravesical (ectopic) is associated with duplex system in children [10]. However, based on the configuration and location of the ureteric orifice Stephen sub classify it into cecoureterocele, stenotic, sphincteric, sphinctersstenotic, blind and obstructed ureterocele [8]. In cecoureterocele, the opening is intravesical but its portion protrude permanently in the bladder neck or urethra giving rise to symptoms of bladder outlet obstruction [1]. This differs from intravesical ureterocele that prolapse with voiding into the bladder neck or urethra causing obstruction [10]. The classification based on the location of the ureteric orrifice as intravesical or ectopic is widely used due to its therapeutic implications. On abdominopelvic ultrasound scan, there may be upper moiety hydronephrosis and cystic outpouching in the urinary bladder giving rise to cyst in cyst appearance [1] Micturating Cystourethrogram may show filling defect and ureteric reflux in duplex system ureterocele [1].

Intravenous urogram may show cobra head deformity and drooping lily sign in duplex system [1]. Occasionally, the entire kidney may not show evidence of excretion on urogram creating a diagnostic dilemma [5]. The most accurate diagnosis can be established by CTU with 3-dimensional reconstruction [11]. The duplex system, ureterocele, hydro-ureteronephrosis of the upper moiety and reflux of the lower moiety ureter and status of the contralateral kidney can be well delineated with or without renal scintigraphy using Dimercaptosuccinic acid (DMSA) [12]. Transurethral endoscopic deroofing is indicated when there is obstruction or infection with good upper moiety function and absence of reflux [1]. The main stay of the treatment of symptomatic duplex system ureterocele is excision and common sheath reimplantation with or without upper moiety nephrectomy when the moiety is nonfunctioning [1]. Open or laparoscopic pyeloureterostomy or uretero-ureterostomy can be done proximally or distally when there is desire to leave the intravesical part intact $[13,14]$. Transurethral endoscopic treatment is associated with the need for secondary intravesical treatment of ureterocele and reflux when done as the initial procedure. The indications for secondary treatments include presence of reflux, persistent hydronephrosis, recurrent febrile urinary tract infection and non-functioning upper moiety [1,13]. Therefore, appropriate diagnosis and treatment of duplex system is challenging. No previous study or report on ureterocele from our environment. We report a case of duplex system ureterocele in 18-year-old lady who had excision of the ureterocele and common sheath reimplantation .

\section{Case report}

Our patient is an 18-year old lady who presented with recurrent right flank pain and intermittent fever of 7 months duration. There was associated storage and voiding lower urinary tract symptoms characterized by urgency, frequency, nocturia, poor urinary stream, straining and incomplete voiding. General examination was normal. There was right renal angle tenderness. Kidneys were not ballotable. The vaginal and rectal examination findings were normal. She had abdominopelvic ultrasound which revealed severe hydronephrosis of right upper moiety, mild-moderate hydronephrosis of the lower moiety system (Figure 1), and a cyst in cyst appearance in the bladder consistent with ureterocele (Figure 2). Intravenous urogram revealed normal excretion in the left kidney and persistent nephrogram on the right and a filling defect in the region of the bladder consistent with severely obstructed right kidney and a ureterocele respectively (Figure 3). Computerized tomographic scan urogram revealed right hydronephrosis of the duplex system, cystic filling defect in the urinary bladder measuring $75 \mathrm{~mm} \times 54$ $\mathrm{mm}$ with characteristic cyst in cyst appearance (Figure 4). The duplex system was missed preoperatively. Urinalysis revealed hematuria of $3+$, urine microscopy showed no microbial growth, electrolyte urea and creatinine were within normal limits. Packed cell volume was $32 \%$, white blood count was $5.9 \times 103 \mathrm{u} / \mathrm{L}$, platelet count of $418 \times 103$. She had abdominal exploration, excision of the ureterocele, ureteral plication of the distal part of the lower ureter and common sheath reimplantation of the 2 ureters (Figure 5). The two ureters were internally stented with size 10 and 8 Nasogastric tubes for upper and lower moiety ureters respectively (Figure 6). The ureteric stents were attached to the urethral catheter to facilitate removal without need for cystoscopy. The retroperitoneal drain was placed. The intraoperative findings were hydronephrotic upper moiety ureter in duplex system inserting in to the urinary bladder below and medial to the lower moiety ureter (Figure 6). Cystic dilatation of the intravesical part of hydronephrotic ureter with stenotic orifice prolapsing into the bladder neck (Figure 6). The lower moiety internal ureteric orifice was located superior to the stenotic ureterocele (Figure 6), as described in Weighert-Meyer rule. She had intravenous antibiotics, fluid and analgesics for 48 hours. She was started on oral feeds subsequently. Ureteral catheter and drain were removed 15 days postoperatively, stitches were removed 16 days post operatively and patients was discharged 20 days postoperatively. She reported an episode of abdominal pain after discharged which resolved with analgesics and antibiotics. Post-operative ultrasound revealed decompressed upper moiety collecting system and collapsed lower moiety system (Figure 7). She is Presently 24 months after the procedure with no complaint. 

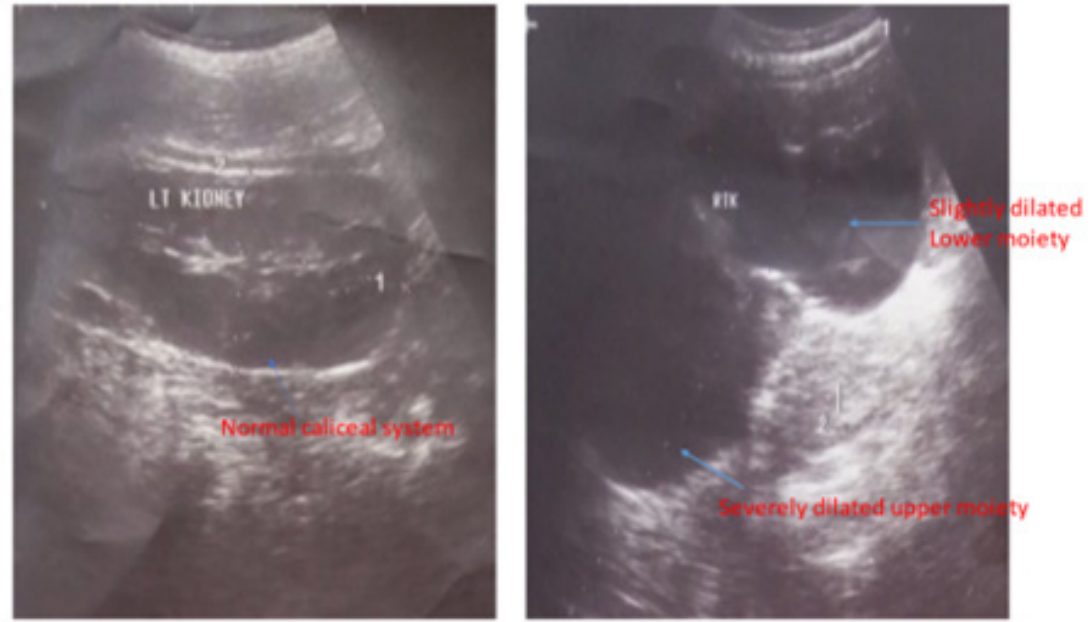

Figure 1: Renal scan showing normal left kidney and right severe hydronephrosis of the upper moiety and mild to moderate hydronephrosis the lower moiety system due to compression by the upper moiety.

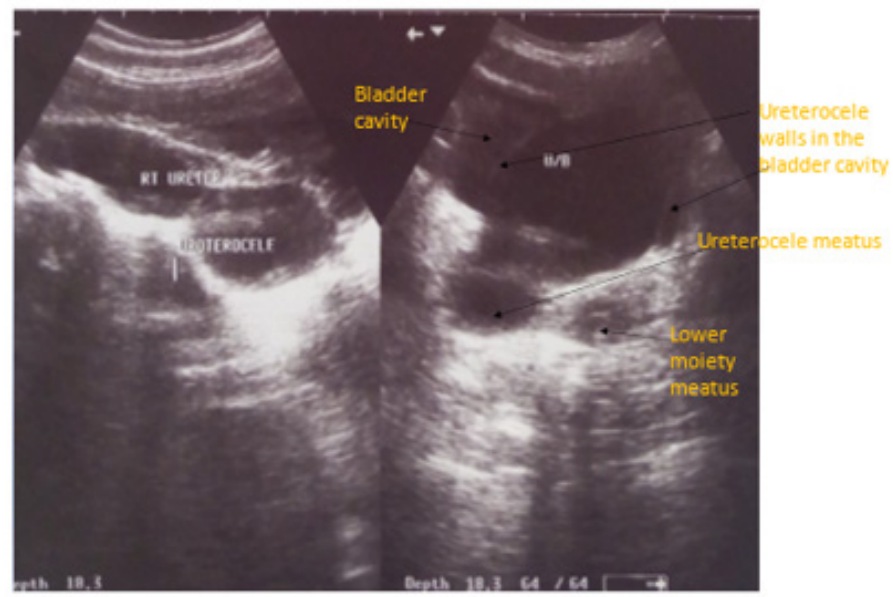

Figure 2: Urinary bladder scan showing ureterocele with the ureteral orifices and cyst in cyst appearance.

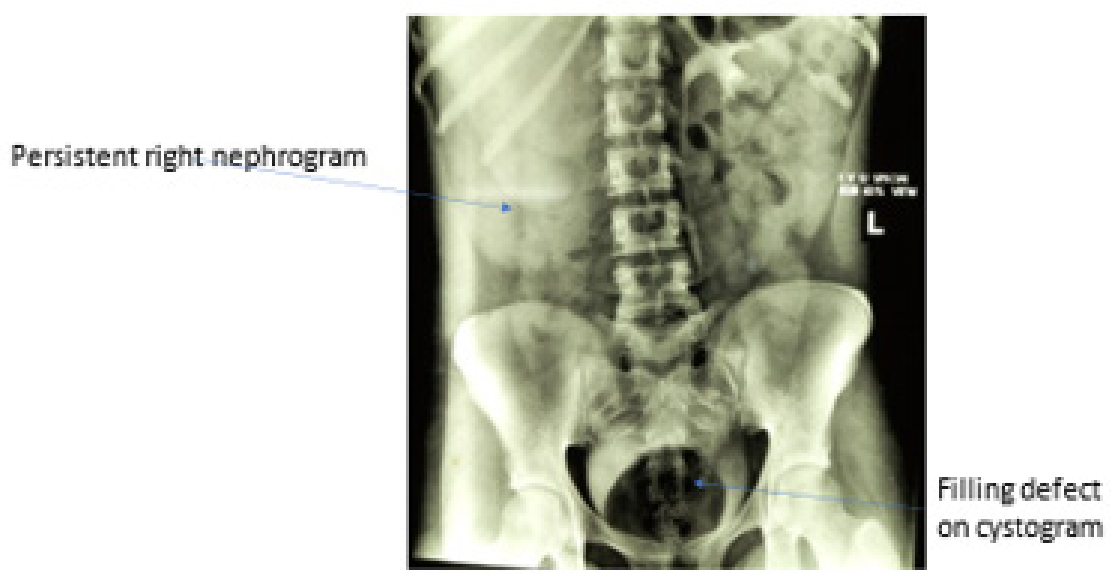

Figure 3: intravenous urogram (IVU) showing normal excretion on the left (L), persistent nephrogram phase of the obstructed right kidney (upper and lower moiety) and filling defect in the cystogram phase consistent with ureterocele. 

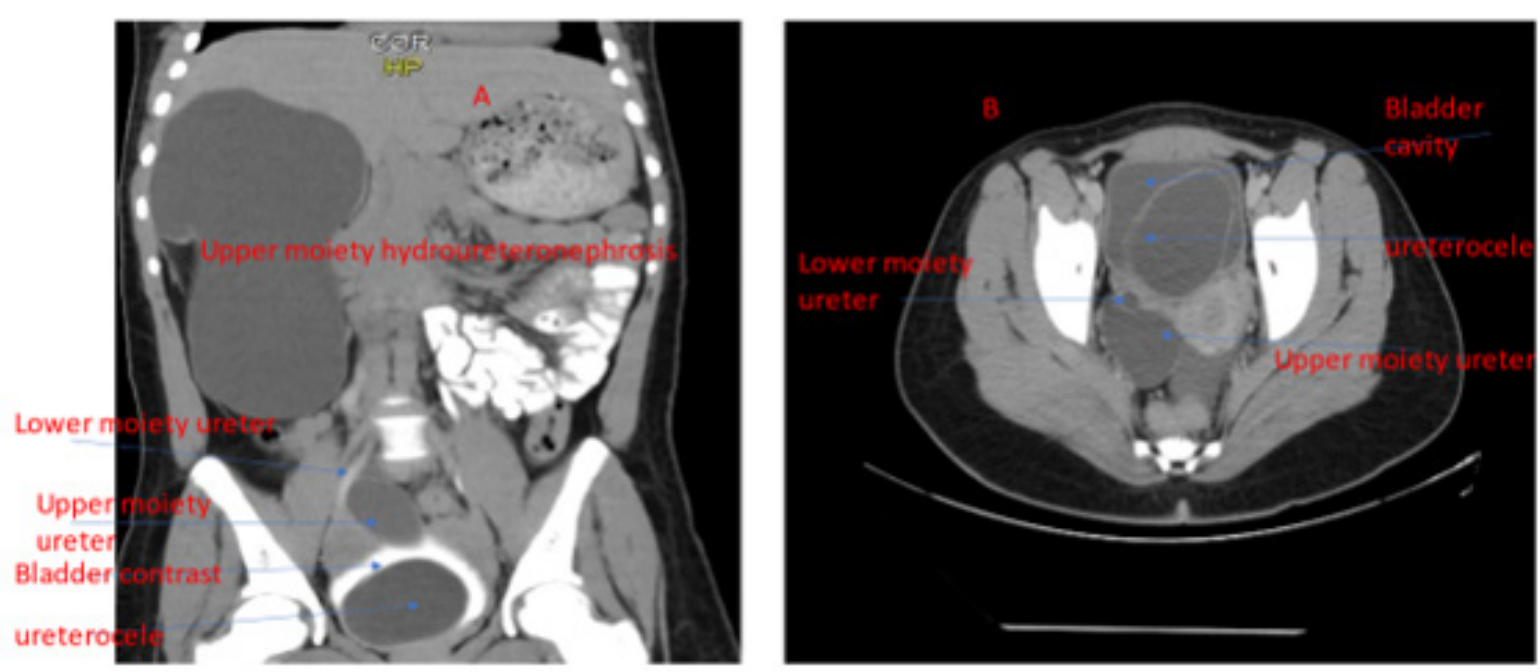

Figure 4: Coronal and axial views of computerized tomographic urogram showing the duplex system and cyst in cyst appearance.

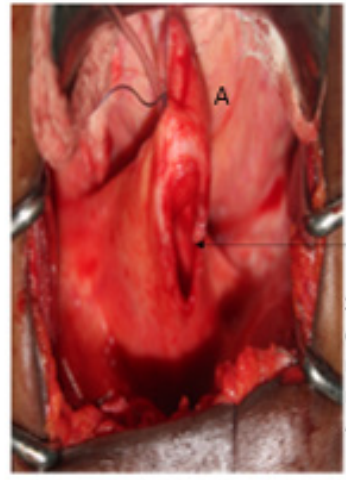

Ureterocele wall

Stenotic ureterocele

extend well below \&

medial to the lower

moiety orifice and

adjacent to bladder neck

Bladder neck

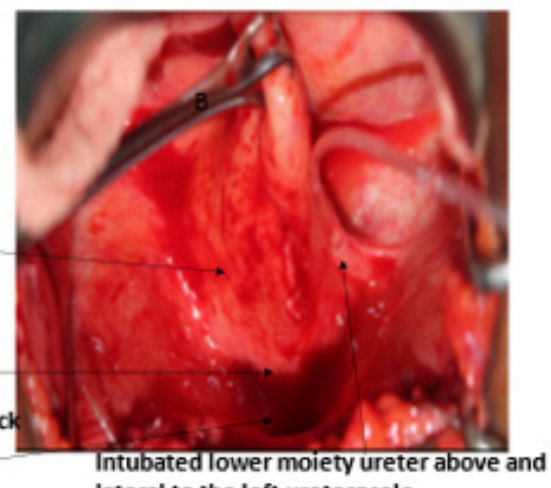

lateral to the left ureterocele

Figure 5: Intraoperative picture showing decompressed stenotic intravesical ureterocele medial and below an intubated lower moiety ureter. The ureterocele is adjacent to bladder which make it possible for the obstructed huge ureterocele to prolapse into the bladder neck during voiding.
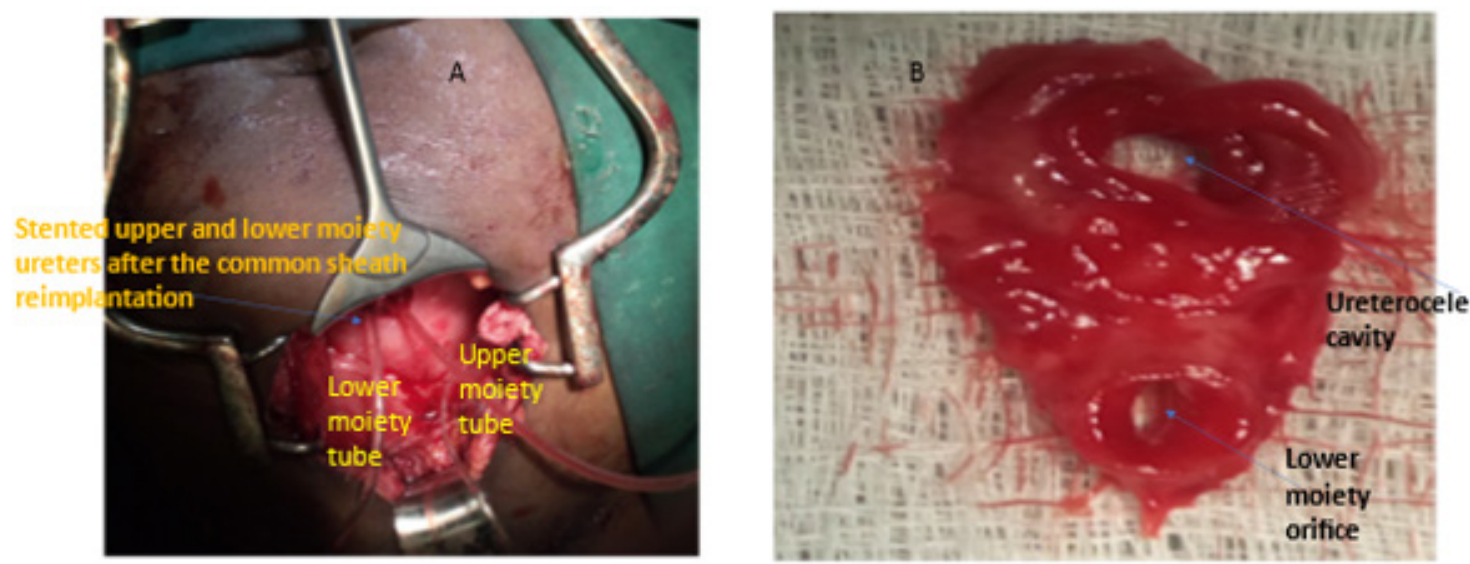

Figure 6: Intraoperative picture of the duplex system after ureterocele excision and common sheath reimplantation (A). B Is the surgical specimen demonstrating ureterocele cavity and lower pole ureteral lumen. 

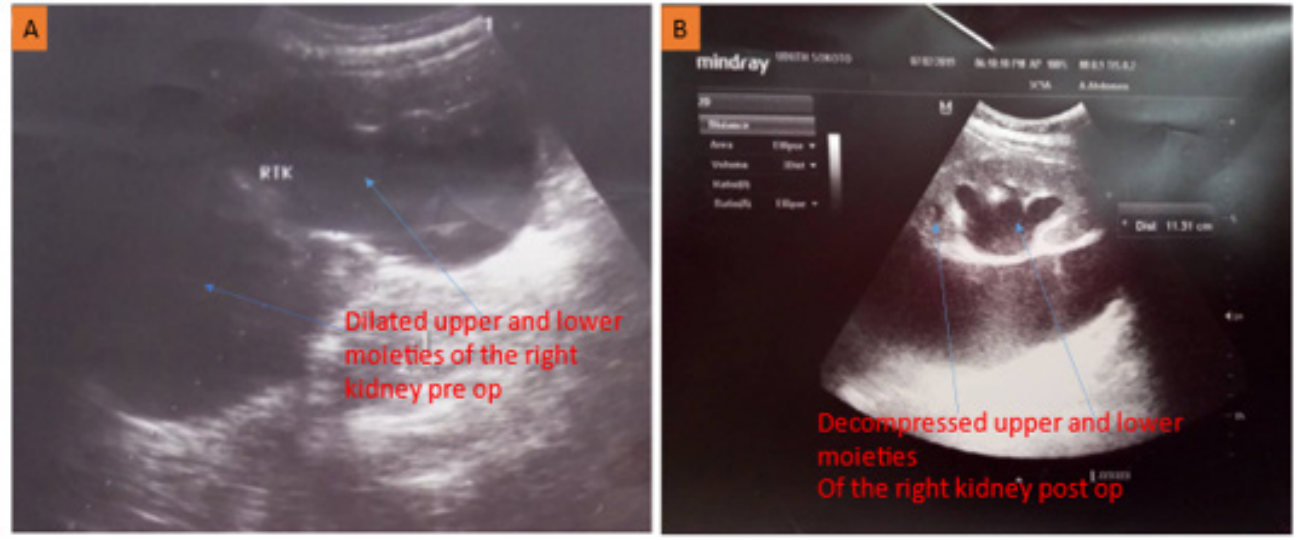

Figure 7: Pre and post-operative Ultrasounds of the Right Kidney showing collapsed lower moiety and decompressed upper moiety.

\section{Discussion}

Ureterocele is cystic dilatation of the intravesical ureter [1]. It may rarely be associated with duplex system and is more common in females [3]. In adult it presents with recurrent urinary tract infection. Imaging studies are the main stay of establishing the diagnosis [3]. Computerized tomographic scan urogram offer the best chance for accurate diagnosis [11]. The treatment can be endoscopic or open. Endoscopic deroofing is curative when the upper pole moiety is functioning normally [13]. Common sheath reimplantation offers the best chance when there is associated reflux [1]. The diagnosis can be missed by initial imaging using ultrasound and intravenous urogram. Secondary surgical procedures may be required when endoscopic incision is done to drain and obstructed or infected system [10]. Our patient is a female which is in agreement with what was reported in literature that duplex system ureterocele in common in female [1]. Our patient is an adult and presented with recurrent febrile pyelonephritis as reported by the previous studies $[1,4,5]$. The index patient had intravesical sphinctero-stenotic ureterocele which prolapse into the bladder neck with voiding leading lower urinary tract symptoms as reported in the literature $[1,3]$. The diagnosis might be challenging and pose dilemma as reported by the previous studies $[5,15]$. The abdominopelvic ultrasound suggests hydronephrosis and ureterocele, no suggestion of duplex system. Both upper and lower moiety systems showed hydronephrosis due to the compression of the obstructed upper moiety on the lower moiety leading to obstruction as reported in the literature [1]. This also impacted on the appearance of the right kidney as persistent nephrogram phase. The lower moiety could not be opacified by the contrast this led to the absence of drooping lily sign. The CTU done revealed hydronephrosis and ureterocele but the duplex system was missed as it is more obvious with reconstructed images as $3 \mathrm{D}$ reconstruction is not done routinely. The intraoperative finding of the duplex system ureterocele in which the upper moiety ureter inserted into the bladder below and medial to the lower moiety ureter is consistent with Wiegert-Meyer rule [1]. The rule states that in duplex system the upper moiety ureter drain into the urinary bladder inferior and medial to the lower moiety ureter and is prone to ureterocele and ectopia while the lower moiety ureter drain into the bladder superior laterally and is prone to reflux $[1,6]$.

Excision of the ureterocele and common sheath reimplantation was done for our patient as reported in the literature $[1,4]$. This offers good chance for normalization of the renal function noted in the post-operative ultrasound scan. The index case has good upper moiety function, so does not require upper pole nephrectomy. The ureterocele was big and the ureter was massively hydronephrotic and lower moiety had short intramural course and open. These made our patient unsuitable for endoscopic deroofing. Such patients have high incidence of reflux post endoscopic treatment and the need for secondary treatment inform of common sheath reimplantation [10]. The patients had good outcome from the open treatment as reported by the literature $[4,5]$. She had an episode of urinary tract infection I month after the surgery. This coincides with the time the system is regaining its tone and function. The limitations of this study include case report, rarity and lack of experience with various options of treatments, endoscopic, upper pole nephrectomy, common sheath reimplantation and short period of follow up.

\section{Conclusion}

Duplex system ureterocele may present with recurrent urinary tract infection in women. Accurate diagnosis may be missed by imaging studies but computerized tomographic urogram with 3-dimensional reconstruction will delineate the pathology with certainty. Common sheath reimplantation is associated with good outcome.

\section{Acknowledgment}

None. 


\section{Conflict of Interest}

No conflict of interest.

\section{References}

1. Peters CA, Mendelsohn C (2016) Ectopic Ureter, Ureterocele, and Ureteral Anomalies Classification and Anatomic Description. General Patterns. In: Wein AJ, Partin AW, Peters CA (eds.) Campbell -Walsh' s Urology. 11th edn. Philadelphia: Elsevier Sunders: 3075-3095.

2. Villanueva CA (2019) Open vs robotic infant ureteroureterostomy. J Paediatr Urol 15(4): 390 e1-390.e4.

3. Stunnel H, Barrett S, Campbell N, Colhoun E, Torreggiani WC (2010) Prolapsed bilateral ureterocele leading to intermittent outflow obstruction. JBR-BTR 93(6): 312-313.

4. Mariyappa B, Barker A, Samnakay N, Khosa J (2014) Management of duplex-system Ureterocele. J Paediatr Child Heal 50(2): 96-99.

5. Timucin S, Hakan A, Ors B (2015) Late Complication of Duplex System Ureterocele; Acute Urinary Retention, Stone Formation and renal Atrophy. Int Arch Urol Complic 1: 2-4.

6. Tanagho EA, Nguyen HT (2013) Embryology of the Genitourinary System. In: Jack W Mc Aninch, Tom F Lue (Eds). Smith and Tanangho's General Urology. Chapter 17. 18th Edition. McGraw Hill Companies. San Francisco, pp.8-40.

7. Mishra K, Elliott CS (2017) A violation of the Weigert-Meyer law-an ectopic ureter arising from the lower renal pole. J Clin Urol 10(3): 202204.

8. Stephen FD, Smith ED, Hutson JM (2002) Congenital anomalies of the kidney, urinary and genital tracts. Informa Health Care pp. 222-225. 2nd edn. (January 15, 2002); Language: English; Hardcover pp. 523
9. Rathbun J, Buatsi EM, Rathbun J (2020) Weigert-Meyer Law Violation with Lower Pole Obstruction and Ectopia. Surg Case Reports.

10. Castagnetti M, Vidal E, Burei M, Zucchetta P, Murer L, et al. (2013) Duplex system ureterocele in infants: should we reconsider the indications for secondary surgery after endoscopic puncture or partial nephrectomy? J Pediatr Urol 9(1):11-6.

11. Croitoru S, Gross M, Barmeir E (2007) Duplicated ectopic ureter with vaginal insertion: 3D CT urography with IV and percutaneous contrast administration. AJR Am J Roentgenol 189(5): W272-W274.

12. Sotelo R, Giedelman C, Carmona O, De Andrade R, Ramírez D (2011) Hybrid-NOTES transvaginal hemi-nephrectomy for duplicated renal collecting system in the adult patient. Actas Urológicas Españolas 35(6): 363-367.

13. Sen V, Aydogdu O, Yonguc T, Bozkurt IH, Polat S, et al. (2015) Endourological treatment of bilateral ureteral stones in bilateral ureteral duplication with right ureterocele. Can Urol Assoc J 9(7-8): E511-E513.

14. John Reynard, Simeon Brewster, Suzanne Biers (2020) Ureterocoele. In: Oxford Handbook of Urology, 2nd edn. Oxford University Press. Oxford pp.632-633.

15. Hodhod A, Noureldin YA, El-Sherbiny M (2017) Is transurethral incision better than upper pole partial? nephrectomy for management of duplex system ureterocoele diagnosed in the first year of life? Arab J Urol 15(4): 319-325. 